\title{
Re-Escribir y Escribir : Arenas, Menard, Borges, Cervantes, Fray Servando
}

No sin cierto humor, Borges conjetura una y otra vez que el universo es una biblioteca, que sus escritos deben entenderse como el testimonio de un lector atento, que la "verdad", de la literatura reside en la repetición de algunas metáforas privilegiadas pertenecientes, siempre, a otros. La escritura borra la individualidad del texto particular y lo integra a la gran biblioteca común, una entidad carente de autores. El gesto tiende a mostrarnos que la "novedad" de los textos es simplemente una ilusión para enmascarar su verdadera naturaleza, la de ser repetición de una instancia de la biblioteca. El arte consistiría en la recurrencia de ciertas insistentes metáforas o historias (estas últimas, también metáforas desde una perspectiva como la de Macedonio y Borges) presentadas en un tono cada vez más simple, más claro. La obra "individual" 'se convierte en el testimonio de una lectura que propone otra. Existe como una figura de su propia inestabilidad; sólo es posible por una relación de analogía con algo distinto y, sin embargo, para efectuar la ilusión de su propia presencia (visibilidad, como diría el reseñador de Menard) debe indicar la fisura que la separa de aquello que desea imitar, de aquello con lo cual desea confundirse.

La obra de Macedonio es, fundamentalmente, una galería de juegos para materializar una literatura de la nada con el objeto de desenmascarar las ilusiones creadoras de la ficción. Sus juegos son redes con una función estrictamente negativa: destruir toda lectura que no vea el texto como re-escritura de otra lectura. Macedonio jugó con personajes que llamaba "ausentes", "inexistentes" y nombró una condición de existencia para sus propios trabajos. Esa condición era un lector de naturaleza especial, alguien capaz de despojarse de ilusiones con respecto a su existencia individual y preparado para materializar la nada a medida que leía, alguien que pudiera leer sólo el ejercicio de lectura. Este era su lector fantástico y, simultáneamente, el escritor ideal.

Existe un entrecruzamiento interesante entre Macedonio y Borges. Para esa red necesitamos un tercer lector (o, por lo menos, uno al que podamos referirnos ingenuamente como tercero por el momento; se multiplicarán más adelante) que fue "creado" por el lector fantástico de Macedonio, Borges. Se trata de Pierre Menard ${ }^{1}$.

"' "Pierre Menard, autor del Quijote." La paginación corresponde a: Jorge Luis Borges, Ficciones (AlianzaEmecé, Madrid, Buenos Aires, 1971) 
Delinear la figura de Pierre Menard como autor es engañosamente fácil. Se propone escribir Don Quijote; una de las alternativas abiertas para hacerlo es convertirse en Cervantes. Su lista de publicaciones muestra a las claras los esfuerzos que debe realizar. Pierre Menard es un poeta del simbolismo francés; debe aprender un idioma extranjero de una época ajena y perder su identidad para ser Cervantes, pero, aún así, el camino parece demasiado fácil:

Ser, de alguna manera, Cervantes y llegar al Quijote le pareció menos arduo -por consiguiente, menos interesante-que seguir siendo Pierre Menard y llegar al Quijote a través de las experiencias de Pierre Menard. (Esa convicción, dicho sea de paso, le hizo excluir el prólogo autobiográfico de la segunda parte del don Quijote. Incluir ese prólogo hubiera sido crear otro personaje-Cervantes-pero también hubiera significado presentar el Quijote en función de ese personaje y no de Menard. Este, naturalmente, se negó a tal facilidad. (p. 53)

Finalmente Pierre Menard logra completar su proyecto: genera unos fragmentos de don Quijote. Se nos aconseja que leamos un fragmento transcripto dos veces y el "análisis de texto" suministrado por el reseñador nos persuade de las diferencias enormes que hay entre ambos dependiendo de quién sea el autor. Como leemos esto en Ficciones sabemos que el mismo reseñador es un personaje desconfiable cuya "información" debe tomarse con cautela. Escribe sobre un Pierre Menard de Nimes que publicó entre principios de 1920 y fines de 1930, y firma su artículo también en Nimes, 1939. La lista de las publicaciones de Menard, suministrada con admiración servil, es una parodia de ciertos amanerados gustos argentinos de fines de la década del veinte, y el intento de escribir Don Quijote es otra instancia de la noción del mapa de tamaño natural como imagen de una literatura que entiende la imitación como confusión total con el referente que quiere nombrar.

El fragmento de Don Quijote transcripto en la reseña es: ... "la verdad, cuya madre es la historia, émula del tiempo, depósito de las acciones, testigo de lo pasado, ejemplo y aviso de lo presente, advertencia de lo por venir." (p. 57) Habla acerca del tiempo y la Historia, los dos factores que parecen separar nítidamente a Cervantes de Menard. Al mismo tiempo, vuelve a dibujar el camino tomado por Menard para ser, simultáneamente, él mismo $y$ Cervantes. El fragmento es la indicación de un puente en el que parecen fusionarse. Se nos pide que lo leamos dos veces para descubrir aquello que lo hace plural; no un texto sino varios, por lo menos dos. Por lo menos dos, como intuimos en $L a$ Modestia de la Historia, ${ }^{2}$ ese otro texto de Borges. El fragmento se convierte en plural y es en esa pluralidad donde reside la maestría de Menard. Ha sido capaz de crear una convención, de mentir. Según el reseñador, Cervantes simplemente copió, repitió lo que en su época era un corriente prejuicio con respecto a la Historia. Menard, en cambio, debe construir una intrincada madeja para, en primer lugar, creer lo expresado en el fragmento y, más tarde, generarlo. Menard debe ser otro, traicionar su época; Cervantes sólo tuvo

\footnotetext{
2 "'La Modestia de la Historia" es un texto interesante para consider la recurrencia de imágenes o metáforas en la literatura.
} 
que ceder y asumir las creencias corrientes en su propio momento. La artificiosidad de Menard es su mayor éxito; la mismidad de sus palabras con respecto a las de Cervantes es una elaborada máscara que esconde una compleja diferencia en la repetición. Distancia, otredad, travestismo son sus virtudes; su maestría es mayor porque sabe producir artificios. Pero todo esto se repliega sobre st. El reseñador es criticado por medio de su propio discurso, hecho de pedantes lugares comunes, frases intelectualoides una estrecha admiración por el "Arte". Al querer repetir a Cervantes como autor, Menard reproduce la emulación de los caballeros andantes de don Quijote. E1 juicio acerca de Menard está inscripto en la obra que intenta reproducir, ya que Menard está contenido en ella. Hay una cadena de imitadores: Don Quijote-caballeros andantes/Cervantes-sabiduría de su época/Menard-Cervantes, que nos devuelve a la relación entre $\mathrm{D}$. Quijote y los caballeros andantes.

"Pierre Menard, autor del Quijote" es, también, una complicación de las nociones de Borges sobre el valor de la repetición en la literatura. Leemos una exageración de su propio proyecto. Si el valor de la literatura reside en la repetición de ciertas metáforas privilegiadas y si consideramos obras enteras como una metáfora, no podríamos pensar que es un gran logrogenerar la repetición de una obra maestra por medio de un fragmento que es, también, una repetición?

Pierre Menard y el reseñador participan de la ilusión de creer que la literatura construye hermosos artificios y verdades esenciales; el juego textual de que ambos son efecto parece indicar que estas verdades no existen $o$, por lo menos, que son de una naturaleza muy modesta. Escribir es reescribir, leer. El ejercicio debe carecer de solemnidad, consiste en someterse a una recurrencia. Es un modo de inscribir el movimiento de imitar algo que es, ya, una imitación.

Pierre Menard es un autor que trata de ser él y otro simultáneamente (El otro, el mismo, como dice Borges en el título de uno de sus libros) y es presentado por un reseñador cuya admiración sirve para denigrarlo. La imitación que Menard hace de Cervantes es tan completa que demuestra que Cervantes era, como él, otro autor. "Pierre Menard, autor del Quijote" es una metáfora del juego textual entre acercamineto y distancia con respecto al texto "original" en el ejercicio de leer (reescribir). El lector pasivo ha sido exagerado al punto de convertirse en su opuesto; ceder a la fuerza del "original" se convierte en el deseo de generarlo. Ficciones pone entre paréntesis el género más explícitamente practicado por los lectores: las reseñas. Está compuesto de reseñas acerca de libros inexistentes escritos por autores apenas existentes. Los reseñadores se implican en los textos por medio de un discurso desconfiable. ¿En qué consiste esta desconfianza? Es un reconocimiento del texto como manipulación; su mayor efecto consiste en crear la duda acerca de todo lo dicho en él; la red que convierte al comentarista en personaje produce la noción de que no debe esperarse ninguna verdad privilegiada delo queidice. Los autores no son los ' dueños"' de su discurso; Menard no puede ser Cervantes porque Cervantes no era él mismo, del mismo modo que Menard no es el mismo. Esta crítica radical del yo, de la individualidad, que parte del "almismo ayoico"' de Macedonio produciría, idealmente, una literatura escrita por nadie, leída por su reflejo y que no transmitiría otra cosa que este intercambio. Esta es la literatura de la materialización de la nada. (Existen juegos análogos en la obra que firman juntos Borges y Bioy Casares bajo los seudónimos de Suárez Lynch, Bustos Domecq y, 
acaso, Montenegro).

Un texto se convierte en el texto ideal si se desenmascara como ficción; debe mostrar el andamiaje que lo hace posible. "Pierre Menard" ataca la noción de autor desde su propio título y, como notamos, efectúa un vacio que impide la fijación de un referente en la narración. Según Macedonio, estos textos constantemente autorreplegándose existirían para ser inmediatamente olvidados, ya que su función es la del provocar el efecto de lectura. El lector perfecto deberia darse cuenta de que el texto no dijo nada, no creó nada y, como consecuencia, no recordaría nada. El texto autodestructivo ideal construiría una red para mostrar la naturaleza secundaria de sus argumentos y personajes, reduciéndolos a simple apoyos para la lectura. Obviamente, Ficciones y gran parte de la obra de Borges y Bioy Casares son ejemplo de estas prefiguraciones. "Pierre Menard" trata de repetir precisamente el momento de don Quijote en el cual su autorazgo parece cuestionable: el párrafo que escribe Menard es de la Parte I, Capítulo IX de don Quijote. Es el momento en que el narrador nos dice que ha encontrado de casualidad unos papeles escritos en árabe, los hizo traducir y leyó la historia de don Quijote escrita por Cid Hamete Benengeli. Este fragmento es precedido por una nota acerca de cómo todos los moros son mentirosos pero, acaso, los historiadores sean diferentes. Don Quijote es presentado como un texto escrito por un moro y filtrado por una traducción.

Al leer "Pierre Menard" hemos diseñado una escena básica: la insistencia de palabras que reaparecen en un texto sin productor fijo. Este vacío de productores es efecto de un juego textual; Pierre Menard repite el movimiento de repetición ya presente en don Quijote. Su proyecto reaparece en El mundo alucinante ${ }^{3}$, novela del joven escritor cubano Reynaldo Arenas. El mundo alucinante es, también, una reescritura. Los textos "originales" son, a primera vista, de naturaleza diferente. Se trata de las Memorias y A pología de Fray Servando Teresa de Mier, un texto autobiográfico y su defensa política en respuesta a sus enemigos. Se necesitan unas breves notas sobre la curiosa vida de Fray Servando Teresa de Mier.

Nació en el entonces Nuevo Reino de León en la Nueva España (Monterrey) en 1763; se hace sacerdote dominicano en 1780 y recibe el título de Doctor en Teología. Su fama como orador hace que lo elijan para hablar en los funerales de Hernán Cortés y también lo lleva a ser comisionado para dar un sermón acerca de la tradición de la aparición de la Virgen de Guadalupe. Este sermón-dado el 12 de diciembre de 1794- causa un gran escándalo y ocasiona denuncias de herejía ante el tribunal de la Inquisición. No entraremos en los detalles del sermón pero será útil recordar las causas por las cuales Fray Servando sufriría penosas consecuencias. Ha habido una cadena de malentendidos en el asunto y los mismos escritos de Fray Servando luego de las acusaciones de sus enemigos han servido para diluir el sentido inicial de sus palabras, si alguna vez lo hubo. Fray Servando negó la tradición hispánica de la aparición de la Virgen de Guadalupe y sugirió (el énfasis depende del modo en que leamos el sermón) que la Virgen de Guadalupe era una máscara de Quetzalcoatl, cosa que sería probada por unos jeroglíficos presentes en su imagen. Quetzalcoatl, desde esta perspectiva, podría haber sido una deidad cristiana revelada a la gente de la región antes de la llegada de los españoles. Toda la visión de las religiones

${ }^{3}$ La paginación corresponde a: Reynaldo Arenas, El mundo alucinante (Editorial Diógenes, México, 1969). 
precolombinas debía ser revisada por el descubrimiento y, como consecuencia, sería minimizado el papel de los españoles como introductores de la verdadera religión siendo este sustituido por un reconocimiento - como más adelante ocurre en la obra de Fray Servando- de su función de conquistadores y opresores de los pueblos americanos.

Los cargos contra Servando son denunciados el día siguiente al sermón y unos días más tarde es puesto bajo arresto en su propia celda del Convento de Santo Domingo. El año en que esto ocurre, 1795 , señala el comienzo de los viajes, juicios y evasiones que han hecho de Fray Servando un personaje tan curioso. De Méjico pasa a un convento en Burgos. Su primera evasión exitosa lo lleva a Francia (alrededor de 1801) donde hay testimonio de discusiones teológicas con rabinos en una sinagoga de Bayonne. En París, adonde se traslada seguidamente, se hace amigo de Simón Rodríguez, el maestro de Bolívar. Trabaja enseñando español y — según su Autobiografía - traduce Atala, de Chateaubriand.

Fray Servando dice una y otra vez en su Autobiografía que el mundo está lleno de farsantes y mentirosos. Un farsante habría robado su traducción y notas de Atala para publicarlas, alteradas, con otro nombre. Fray Servando pasa su vida escribiendo contra sus enemigos y haciendo querellas legales. Después de conseguir su secularización del Papa viaja de Francia a España y de allí a Italia. En 1816 se une a las fuerzas que luchan contra los españoles; cae en prisión nuevamente y escapa de un continente a otro. Después de la independencia mejicana regresa a Méjico de su prisión en España pero es encarcelado nuevamente debido a sus discursos contra Iturbide. Los últimos tres años de su vida transcurren en una atmósfera comparativa tranquila. Es representante de Nuevo León en el Primer Congreso Constitucional Mejicana después del triunfo de las facciones antiIturbide. Pero aún entonces, juega un papel de opositor; sus opiniones son de tal naturaleza que se convierte en una figura aislada. Su último discurso público en noviembre de 1827 (muere el 3 de diciembre de ese año) es, en parte, una defensa contra acusaciones que se le habian hecho.

Fray Servando Teresa de Mier fue un escritor prolífico. Reynaldo Arenas ha elegido leer varios de sus trabajos para su novela. Son la Apologia (escrita en 1819), donde habla fundamentalmente de sus evasiones y otros hechos curiosos como su negativa de casarse con una hermosa judía, un intento de evasión en el cual usó un paraguas como paracaídas, descripciones de los países por donde viajó (sus "observaciones" de la vida cotidiana le permiten retratar a los españoles, por ejemplo, como libertinos con mujeres semidesnudas por las calles y al clero como una banda de analfabetos), estafas tales como hacerse pasar por Obispo de Baltimore, peleas con varias burocracias; y la Carta de despedida a los mexicanos escrita desde el Castillo de San Juan de Ulúa (1821), donde intenta elaborar una teoría de interpretación de jeroglíficos capaz de testimoniar la esencia cristiana del Méjico precolombino.

El juego entrevisto en Menard era una complicación de la problemática que surge al intentar fijarle un productor al texto que leemos. Este juego de complicación de la noción de autor comienza por una novela, don Quijote. Leeremos estas preguntas en Arenas referidas a un discurso que es, aparentemente, de naturaleza distinta, un espacio donde el problema de la "verdad", de un referente anterior al texto se revela con mayor insistencia. El mundo alucinante comienza con una carta que propone, desde el principio, el proyecto de Menard burlándose del tipo de identidad expresado por la firma-Reynaldo Arenas-que la 
sigue :

...No obstante, la acumulación de datos sobre tu vida ha sido bastante voluminosa; pero lo que más útil me ha resultado para llegar a conocerte y amarte, no fueron las barumadoras enciclopedias, siempre demasiado exactas, ni los terribles libros de ensayos, siempre demasiado inexactos. Lo más útil fue descubrir que tú y yo somos la misma persona. De aquí que toda referencia anterior hasta llegar a este descubrimiento formidable e insoportable, sea innecesaria y casi la deshechado por completo. Sólo tus memorias, escritas entre la soledad y el trajín de las ratas voraces, entre los estallidos de la Real Armada Inglesa y el tintinear de los mulos por los paisajes siempre intolerables de España, entre la desolación y el arrebato, entre la justificada furia y el injustificado optimismo, entre la rebeldía y la huída, entre el destierro y la hoguera; sólo ellas aparecen en este libro, no como citas de un texto extraño, sino como parte fundamental del mismo, donde resulta in necesario recalcar que son tuyas; porque no es verdad, porque son, en fin, como todo lo grandioso y grotesco, del tiempo; del brutal e insoportable tiempo que en estos días te hará cumplir doscientos años. (pp. 9-10)

A pesar de la afirmación "que tú y yo somos la misma persona", el descubrimiento es que ambos son otra persona. El intercambio entre tú y yo no consiste de una pluralidad no problemática que preserve la identidad de cada uno para sí. Es, por el contrario, e1 descubrimiento del cambio constante de un pronombre por otro, no simplemente el pasaje de un tú a un yo. Esa misma persona que parecen devenir es una figura de la circulación dentro del sistema de pronombres personales. Esa misma persona es nadie; es, al mismo tiempo, todas las personas. Por eso leemos la consecuencia, áparentemente paradójica, de que el libro contiene a las Memorias de Fray Servando como parte fundamental, pero con un papel distinto del de una cita. ¿Dónde reside la paradoja? El texto elegido de toda la bibliografía de y sobre Fray Servando para figurar explícitamente (sabemos que hay otros dos incluidos) en la novela son sus memorias. Las memorias parecen rescatar aquello que fuera destruido: la identidad de Fray Servando con respecto a sí mismo en la forma de una autobiografía. Su "vida" en un texto está contenida en El mundo alucinante, un libro con un nombre distinto del suyo, con una diferencia que denota el pasaje de lo singular al plural. De Fray Servando (un nombre propio) al sustantivo que más abarca, el mundo. De la individualidad del nombre propio a una palabra que nombra al mundo.

Otra vez, el Borges de "El Aleph" y "El Zahir' implica y está implicado en este texto. El problema reside en la simultaneidad de nombrar. Dicho de otro modo, si la otra persona no es yo ni tú sino una constante oscilación de los pronombres personales que simultáneamente los presenta y borra, ¿cómo construir un discurso que asuma esa oscilación? ¿Cómo sería un texto que partiera de un entendimiento del proyecto de Pierre Menard como disolución de los autores en una forma análoga al modo en que el intercambio de pronombres personales termina borrando la noción de persona anterior al discurso? Las respuestas dibujarán una figura para esa otra persona creada por la lectura de las memorias de Fray Servando. Nuestra primera lectura considerará a la novela como una elaborada reescritura de las Memorias, dándole a éstas el papel de una fuente "originaria'. 
La primera pregunta que formulamos es: ¿en qué juego participa el autorazgo de las memorias al integrarse a la novela? Seguiremos un camino análogo al primer movimiento de "Pierre Menard"; se tratará de descubrir cómo el productor se convierte en otra persona.

La novela tiene tres capítulos número uno, tres rapítulos número dos y un curiosamente espaciado y plural número tres. La aparición de cada capítulo número uno cerca del otro ayuda a intensificar el efecto de oscilación en la elección de cómo comenzar la lectura de la novela. Los tres capítulos número uno tienen los siguientes títulos en este orden: "De cómo transcurre mi infancia en Monter rey junto con otras cosas que también transcurren"; "De tu infancia en Monterrey junto con otras cosas que también ocurren", "De cómo pasó su infancia en Monterrey junto con otras cosas que también pasaron', Recurre el de en las tres versiones y hay un cambio en los verbos usados para cada caso: transcurrir, ocurrir, pasar.

Estos títulos son subtítulos para distintos capítulos número uno; son casi el mismo subtítulo. La diferencia entre ellos está dada por el pronombre personal y los verbos usados para indicar el pasaje del tiempo. El comienzo de cada subtítulo con de sugiere que se nos va a decir algo acerca de algo, la existencia de un tema. El tema sería una infancia que transcurre, ocurre, pasa. Cada subtítulo parece estar implicado y luego desplazado por el otro. La variación de los pronombres personales y los verbos muestra la función de enmascarar que asume la insistencia del $d e$. No hay, en verdad, tema sino la presentación del movimiento que crea temas como efecto de un juego textual. La mismidad de lo "dicho", en cada uno de los subtítulos implica diferencia, la existente entre transcurrir, pasar, ocurrir y la que hay entre los pronombres. Cada uno de los verbos se convierte en traducción del otro; la oscilación creada por el hecho de que cada uno lleva el número uno da la ilusión de la posibilidad de elegir distintos comienzos para la novela; de una elección que pueda sustraernos de la ambiguedad de un comienzo dividido en tres intentos del mismo gesto, condenado a la pluralidad y la fragmentación. Otro comienzo que no se cuestione como el único número uno.

Cada subtítulo está, también, dividido en dos partes que forman la figura de la traducción ( traducción como un ejercicio que, bajo el gesto de decir lo mismo, repetir, se inscribe como separado de aquello que nombra). La segunda parte repitela primera parte del subtítulo en un plural referido a "otras cosas". El verbo usado es el mismo, cada parte es un juego con distintas formas de ese verbo: el singular y el plural. (Significativamente, el segundo capítulo número uno, el que usa ocurrir, no tiene esta división y sugiere, así, unidad en el hecho que ocurre). Elegir uno solo de los subtítulos no superará la pluralidad porque cada uno es una pluralidad en sí mismo. Los tres números uno se burlan de la noción de comienzo y sugieren una elección frustrada por cada uno de los subtítulos. Los verbos utilizados nombran al tiempo. Pero, no obstante, leemos la parte más " ahistórica", de la novela ; parece una continuación de esa otra novela " "prelógica" de Arenas, Celestino antes del alba. Hay una coexistencia entre vivos y muertos, un espacio común donde la supresión del tiempo parece posible:

Yo eché a correr por entre los troncos de las matas de corojos, llamando a mi madre. Pero en esos momentos mi madre estaba desemillando algodón--para 
sacarle el hilo--para hacerlo tela para venderla--para comprar un acocote para cuando llegara el tiempo de sacar al aguamiel--para sacarla--para hacerla pulque-para venderlo--para comprar cuatro maritates--para regalarlos al cura--para que nos volviera a bendecir el ganado--para que no se nos muriera como ya se nos murió. Además: también ella estaba muerta. (p. 12)

La repetición de para enfatiza la sucesión: una cosa debe ser hecha de modo que otra siga; los guiones de separación intensifican el efecto. Pero la cadena se interrumpe por la presencia del tiempo: ella estaba muerta. La cadena es, en verdad, inexistente. Muestra el movimiento ilusorio de la sucesión: la madre, el cura, el ganado, cada una de las tareas, todo existe simultáneamente. Pero, aún así, la clave para la realización de este efecto es la causalidad: la simultaneidad se logra por un juego textual que contiene sucesión.

Las primeras palabras del primer capítulo número uno siguen a un subtítulo escrito en la primera persona del singular. Es un yo quien habla:

Venimos del corojal. No venimos del corojal. Yo y las dos Josefas venimos del corojal. Vengo solo del corojal y ya casi se está haciendo de noche. Aquí se hace de noche antes de que amanezca. En todo Monterrey pasa así: se levanta uno y cuando viene a ver ya está oscureciendo. (p. 11)

¿Quién es ese yo? Primero hay un nosotros que viene con las dos Josefinas, las Hermanas Iguales. Pero no lo hace. Se presenta como individuo, ya que tiene la posibilidad de compartir un plural con sus hermanas. Una vez que ha mostrado que es una primera persona en el sentido de que funciona así en relación a otros, una vez que ha logrado diferenciarse como pronombre, niega la afirmación: "Vengo solo..." Reaparece la negación de la sucesión por medio de su uso, que habíamos notado. Los capítulos reproducen el movimiento de los subtítulos. Son, como ellos, presentación de alternativas que impide la elección de cualquiera de ellas en detrimento de las otras. El juego precisa la orquestación de alternativas, lo importante es el juego textual y no cada uno de los elementos por separado.

Yo, tú, él, nosotros, vosotros, ellos. Estos son los términos puestos en juego en los tres capítulos que llevan el número uno. Si esto debe ser entendido como un juego textual entre los pronombres que impide la definición de cada uno de ellos como entidades separadas, el problema del productor del texto se integra al sistema de interdependencia ya que él no es otra cosa que uno de esos pronombres. Esta fluctuación tiende a construir un discurso descentrado.

El capítulo dos ocurre, también, tres veces y representa un juego pronominal. Los subtítulos son: "De mi salida de Monterrey", "De la salida de Monterrey"'; "De tu salida de Monterrey', Los textos se apartan de la apariencia "ahistórica', de los anteriores ya que el camino a la cuidad de Méjico se etiriquece con alusiones que ayudan a fijar el momento de la partida (entre elias la fecha de la construcción de la Catedral de Méjico). Fray Servando emerge como una figura histórica. Comienza la construcción de un lenguaje que hará una suerte de mímica con respecto a las Memorias; este aspecto aproxima a Menard y Arenas. La partida de Monterrey no es sólo la recurrencia de los juegos 
pronominales indicados sino, también, otro comienzo porque introduce a la Historia como una determinante con importancia en el discurso. La partida de Monterrey es un camino hacia Méjico; es, además, el camino hacia la "vida" pública de Fray Servando.

El comienzo de una vida histórica parece sugerir que la figura de abolición del tiempo por medio de la orquestación de distintas alternativas para el acto de comenzar ha llegado al momento decisivo de elegir entre una de esas alternativas. Pero no es así. Por el contrario, las alternativas reaparecen de modos más interesantes e intensos. Los capitulos que llevan el número dos han integrado en sus tres partes conflictivas el juego entre los capítulos número uno. El capítulo número tres, "Del panorama de la cuidad" aparece sin el ya obvio movimiento de los otros expresado por la repetición de los números. Es una puesta en escena de la cadena sugerida por una de sus oraciones: "siguió a la turba que seguía a la vez a una mujer, que seguía a una soga que la llevaba arrastrada por el cuello." (p. 20); la prolija sucesión de quién sigue a qué es parodiada por: "También el mantenimiento de la hoguera era un gran problema y para ello se empleaba a un millar de indios, que debían abastecer aquellas llamas día y noche, sacando leña de donde fuera, y en situaciones críticas servian ellos mismos de combustible. Pero algunos no esperaban a que se tomasen tales resoluciones y, cansados de tan continua búsqueda, se lanzaban (con la poca leña que habían encontrado) a las llamas y de esta manera la iban atizando por un rato." (p. 21) Aquellos que prenden el fuego se arrojan a él para hacerlo arder. La distinción entre el productor y su producto es oscurecida por un sistema básicamente inestable en el cual sus funciones se intercambian; esto surge del movimiento del texto. No necesitamòs el ejercicio de traducción de los capítulos número uno y dos porque este número tres está dividido, en sí mismo, en por lo menos tres partes. $\mathrm{Y}$ es nuevamente la violencia de los pronombres personales en su tendencia a desplazar al otro y,de ese modo, cancelarlo la que produce el vacío.

El mundo alucinante trabaja con datos históricos, sigue lo que puede ser considerado como la "vida" de Fray Servando pero, sin embargo, destruye constantemente la linealidad cronológica por medio de la oposición de elementos contradictorios como, por ejemplo, el momento en el cual Fray Servando se pasea por la calle que lleva su nombre. La imposibilidad de elegir entre alternativas opuestas no ordenadas jerárquicamente existe en todos los capítulos de la novela y cumple la función de poner entre paréntesis la noción de progreso narrativo.

El capítulo número siete es, otra vez, tres capitulos. También es otro comienzo en el sentido en que es el punto de partida de ese otro libro que la novela intenta ser: las Memorias de Fray Servando Teresa de Mier. Las Memorias son precedidas por la Apologia, texto en el cual Fray Servando se defiende de los ataques provocados por su sermón acerca de la Virgen de Guadalupe y sugiere que su "vida" es consecuencia del sermón. Los tres números siete tienen los siguientes títulos en este orden: "De las consecuencias del sermón"; "De la consecuencia del sermón"; "De la consecuencia del sermón'. El capítulo número seis tiene una imagen que califica la naturaleza plural de este nuevo comienzo: "y el cielo haciéndose pedazos, daba acceso a Las-Nuevas-ImágenesRecuperadas."' (p. 39) Las imágenes son nuevas $y$ recuperadas. Son plurales pero pueden efectuar oblicuamente la ilusión de su singularidad; cada punto de partida es simultáneamente, un ir hacia atrás. El exceso de material cronológico produce un vacio histórico. 
El texto se convierte en un movimiento que no lleva hacia ningún lado en línea recta sino que se difunde en múltiples direcciones.

"Consecuencias" en plural en el primer capítulo número siete parodia el singular que sigue. Pero, ¿qué sabemos de aquello que produce la consecuencia, del sermón? En el capítulo "Del conocimiento de Borunda" leemos acerca del encuentro con un personaje que es "algo así como una gran pipa que se movía y hablaba, pero más gorda" (p. 33). Esa gran pipa tiene una teoría que redefine la tradición de la Virgen de Guadalupe. El encuentro ocurre en una cueva; Fray Servando y Borunda hablan sentados sobre esqueletos, rodeados de murciélagos. Borunda le dice a Servando susermón; le cuenta que "la imagen de Nuestra Señora de Guadalupe es del tiempo de Santo Tomás a quien los indios llamaban Quetzalcoatl' ' (pp. 33-34. Ese es el sermón de Fray Servando. Adquiere el status de una cita de un libro que no leyó, ya que Borunda alude a la existencia de un texto donde sus teorías están fundamentadas pero Fray Servando no tiene acceso a él. El sermón sólo le pertenece a Fray Servando en apariencia, no es responsable de él; su voz produce el efecto de un autorazgo que, en verdad, no existe.

El plural del primer capitulo número siete refleja la pluralidad de productores--por lo menos dos--del sermón. El sermón le "ocurre" a Fray Servando. Sus palabras son "un largo combate entre los antiguos dioses y las nuevas leyendas"' (p. 38). Fray Servando, Borunda, el público se sustituyen los unos a los otros. Hay un movimiento que produce la ilusión de un discurso con productores fijos pero, al intercambiar sus posiciones, crean una continuidad que supera las identidades individuales, destruyéndolas y reemplazándolas.

Así como la Virgen de Guadalupe contiene y es contenida por Quetzalcoatl, El mundo alucinante contiene y es contenido por otros libros. ¿Qué papel cumplen las Memorias y la Apología en la novela? ¿Hasta qué punto pueden ser entendidas como 'fuentes originarias" de la novela? Fray Servando asegura en esos trabajos que, por un lado, el sermón no le pertenecia y que, por otro, fue malinterpretado. Dio el sermón por influencia de Borunda pero ni bien tuvo la oportunidad de leer el libro de Borunda disintió con él. (No es inútil recordar que en su Carta de despedida a los mejicanos desde el Castillo de San Juan de Ulúa, también contenida en la novela, Fray Servando desarrolla una teoría no menos disparatada que la de Borunda; se basa también en una cierta interpretación de jeroglíficos para sacar consecuencias sobre la ortografía de algunas palabras. Los entrecruzamientos con la tesis de Borunda son múltiples.) A pesar do todo esto, Fray Servando sostiene que el sermón no fue un error. No decía lo que el público creyó oir (sugiere que su tono sobre lo dicho no fue positivo y desarrolla una compleja teoría sobre la necesidad de predicar cosas posibles, no necesariamente ciertas) y, en todo caso, quien hablaba era Borunda a través de su propia voz, con un discurso ciertamente oblicuo, ya que Fray Servando no había leído su libro en el momento de su prédica. Simultáneamente, Fray Servando se une al público en la condenación de Borunda.

La Apología es un texto que trabaja en múltiples direcciones. La primera persona que escribe esta defensa y las Memorias se delinea como tal en un combate contra sus enemigos pero comparte sus opiniones y se confunde con ellos; estos textos son el producto de un lector. En ambos Fray Servando culpa a sus enemigos por no estudiar lo suficiente si pertenecen al clero y por desconocer los escritos de Bartolomé de las Casas y otros si son políticos racistas. La inferioridad que ve en los españoles la atribuye a que leen poco y a 
que, en verdad, son un pueblo analfabeto. Sus enemigos lo son por ignorancia; Fray Servando se ve a sí mismo como una figura construida por el prejuicio y la falta de lecturas.

El mundo alucinante es metáfora de la oscilación de los textos de Fray Servando, de su "vida" entendida como la reescritura de una teoría que no conocía del todo pero que está, no obstante, implicada en su biografia. El mundo alucinante juega con la figura de las atribuciones de Borges al negar la posibilidad de distinguir un solo productor del texto. Pierre Menard eligió ser él y Cervantes al mismo tiempo y en esta fusión diseñó un movimiento oscilatorio entre el S. XVII y el S. XX; El mundo alucinante parece intentar un gesto de fidelidad histórica que, sin embargo, se subvierte constantemente.

El reseñador de "Pierre Menard, autor del Quijote"' nos dice que Pierre Menard decidió dejar de lado las etapas intermedias de su tarea y que sólo leeremos un fragmento de sus logros. ¿Qué falta? ¿Cuáles fueron esas etapas intermedias? Precisamente las que permiten la lectura doble del fragmento, las que marcan la oscilación entre Menard y Cervantes, el momento en el cual Menard está por convertirse en otro. Esas etapas intermedias son El mundo alucinante. El juego intertextual entre pronombres es lo que la novela ofrece como ilusión de su productor y eso es precisamente lo que Menard oculta. Menard no muestra las dificultades de pasaje de su lengua nativa al español del Siglo de Oro; su aprendizaje es simplemente mencionado por el comentarista. En el heterogéneo discurso de El mundo alucinante hay una coexistencia, una fluctuación entre el español contemporáneo y el de la época de Fray Servando. El juego de palabras por el cual fraile repetido se convierte en fraude (fraile/fraile/fraude) es un modelo reducido del discurso de la novela, hecho de palabras que están en el proceso de convertirse en otras pero que, no obstante, tienen un resto que las preserva (en este caso, la similitud de sonido inscribe la posibilidad de esa preservación).

En "Pierre Menard, autor del Quijote" encontramos el juego de atribuciones existente en la parte del Quijote de la cual toma su fragmento representado (en el sentido teatral del término) en la forma de notas al pie y trabajos individuales de Menard (las traducciones literales de traducciones literales, transposiciones, etc.) Los últimos capítulos de El mundo alucinante repiten este movimiento que consiste en establecer núcleos en la narración que repliegan el texto sobre sí. Esto aparece en la forma de un político--Victoria Guadalupe--cuyo nombre sintetiza simultáneamente la vida de Fray Servando y la novela; también en la frenética escritura de Apologías que ocupa a varios personajes y en la parodia que Heredia escribe acerca de un poema aún no escrito. El mundo alucinante parece partir de un género con una relación directa con "la verdad": autobiografías escritas por un historiador. Pero al delinear la relación de Fray Servando con la Clave para los Jeroglificos A mericanos de Borunda hemos develado el mismo gesto de Menard: la imposibilidad de distinguir un productor único del texto creada como efecto de la atribución de autorazgo al productor de otro texto, igualmente cuestionado. (A caso debiéramos recordar que el autor de la Clave para los Jeroglificos Americanos no posee una identidad más clara que Cid Hamete Benengeli.)

Estos textos se constituyen como tales por repetir otros que son, a su vez, repeticiones. De este modo se ofrecen como obras que sólo producen el efecto de lectura desde una perspectiva como la de Macedonio Fernández.

Ha llegado el momento de preguntarnos cómo hablan estos textos e en contra de sí 
mismos, en contra de su teoría de develar la máquina de la ficción replegándose sobre su propio discurso al mismo tiempo que parecen diluirse en una repetición infinita que no reconoce ninguna fuente originaria. La base del intento es, nuevamente, la "verdad". Esta sospecha, esta desconfianza con respecto a textos que ocultan cómo están constituidos, esta escritura de obras radicalmente autorreflexivas supone una teoría tan convencional y proclive a la producción de ilusiones acerca de șí misma como la de los textos que se propone negar. El sueño del texto perfecto que sólo produzca el efecto de lectura, es decir, que sugiera el lenguaje en pura fluidez, también implica una máquina de ilusiones. La distancia radical con respecto a la "vida" y los referentes fijos presupone una oscilación que crea sus propias convenciones para materializar la ausencia. Esta ausencia está en conflicto constante consigo misma ya que al constituirse en un texto individual se convierte en su propio opuesto.

Reynaldo Arenas en $E l$ mundo alcinante y Borges en "Pierre Menard, autor del Quijote" crean máquinas que tienden a enmascararse como una lectura vista como reescritura. Este efecto de repetición implica una ilusión tan fuerte como la de la tradición realista que pretenden negar; no se nos pide que pensemos que en vez de libros leemos "vida", se supone, en cambio, que olvidemos el libro, lo borremos y creamos que es la teoria del lenguaje que lo hace posible.

The Jobns Hopkins University

ALICIA BORINSKY 